\title{
Phase II trial of modified FOLFOX6 and erlotinib in patients with metastatic or advanced adenocarcinoma of the oesophagus and gastro-oesophageal junction
}

\author{
ZA Wainberg*,I, L-S Lin², B DiCarlo², KM Dao², R Patel ${ }^{2}$, DJ Park², H-J Wang ${ }^{3}$, R Elashoff ${ }^{3}$, N Ryba ${ }^{2}$ \\ and JR Hecht
}

'Division of Hematology/Oncology, Department of Medicine, Geffen School of Medicine at UCLA, Los Angeles, CA, USA; ${ }^{2}$ Translational Oncology Research International (TORI), Los Angeles, CA, USA; ${ }^{3}$ Department of Biostatistics, Geffen School of Medicine at UCLA, Los Angeles, CA, USA

\begin{abstract}
BACKGROUND: There is increased recognition that cancers of the upper Gl tract comprise distinct epidemiological and molecular entities. Erlotinib has shown activity in patients with adenocarcinoma of the oesophagus/gastro-oesophageal junction (GEJ), but not in distal gastric cancer. mFOLFOX6 is one of several active regimens used to treat adenocarcinoma of the Eso/GE). This study evaluates the efficacy and safety of mFOLFOX6 and erlotinib in patients with metastatic or advanced Eso/GEJ cancers.

METHODS: Patients with previously untreated advanced or metastatic Eso/GEJ adenocarcinoma are treated with oxaliplatin $85 \mathrm{mg}^{-2}$, 5-FU $400 \mathrm{mg} \mathrm{m}^{-2}$, LV $400 \mathrm{mg} \mathrm{m}^{-2}$ on day I, 5-FU $2400 \mathrm{mg} \mathrm{m}^{-2}$ over $48 \mathrm{~h}$ and erlotinib $150 \mathrm{mg}$ PO daily. Treatment was repeated every 14 days. The primary objective was response rate (RR), secondary objectives include toxicity, progression-free survival (PFS), overall survival (OS) and to correlate clinical outcome with expression patterns and molecular alterations in the epidermal growth factor receptor-dependent pathways.

RESULTS: A total of 33 patients were treated and evaluable: there were two complete responses, 15 partial responses for an objective RR of $51.5 \%$ (95\% Cl, 34.5-68.6\%). Median PFS was 5.5 months (95\% Cl, $3.1-7.5$ months) and median OS was 11.0 months (95\% Cl, 8.0 - 17.4 months). The most common grade 3-4 toxicities were: diarrhoea (24\%), nausea/vomiting (I I\%), skin rash (8\%) and peripheral neuropathy (8\%). The frequency of alterations was KRAS mutations (8\%), EGFR mutations (0\%) and HER2 amplification (19\%).

CONCLUSION: In patients with Eso/GEJ adenocarcinoma, mFOLFOX6 and erlotinib is active, has an acceptable toxicity profile and FOLFOX \pm erlotinib could be considered for further development.

British Journal of Cancer (20II) I 05, 760-765. doi:I0.1038/bjc.20II.280 www.bjcancer.com
\end{abstract}

Published online 2 August 201I

(c) 20II Cancer Research UK

Keywords: oesophagogastric cancer; erlotinib; EGFR; FOLFOX

\begin{abstract}
Adenocarcinoma of the stomach is the most common gastrointestinal cancer in the world and the second leading cause of cancer death worldwide (Jemal et al, 2009). Although there is significant geographic variation in this disease, recent trends in incidence have suggested that gastro-oesophageal junction (GEJ) adenocarcinomas are among the fastest growing malignancies in the Western world (Blot and McLaughlin, 1999). Furthermore, despite significant evidence that adenocarcinomas of the GEJ have distinct epidemiologic and pathologic features; they are often grouped with distal gastric cancers in clinical studies (Marsman et al, 2005). Therefore, novel investigational approaches are needed for this subset of upper gastrointestinal tract cancers in order to improve outcomes.

In patients with metastatic gastric and oesophageal adenocarcinomas, the median overall survival (OS) ranges between 7 and 10 months. Most studies in oesophageal and gastric cancers have included fluoropyrimidines and platinums as the backbone
\end{abstract}

*Correspondence: Dr ZA Wainberg; E-mail: zwainberg@mednet.ucla.edu Received I June 201।; revised 28 June 201।; accepted 8 July 201।; published online 2 August 201। of these therapies, with some regimens containing a third chemotherapeutic agent. A randomised phase III trial demonstrated that the combination of fluorouracil and oxaliplatin was at least equivalent to if not better than fluorouracil and cisplatin with an improved toxicity profile (Al-Batran et al, 2008). In addition, the REAL-2 trial demonstrated that the triplet regimens, which contained oxaliplatin in place of cisplatin showed similar efficacy. In these trials, the median OS times were 10.7 and 11.2 months, respectively (Cunningham et al, 2008).

The epidermal growth factor receptor (EGFR) is a transmembrane glycoprotein that is part of the human EGFR (HER) family. As in many epithelial malignancies, oesophageal and gastric cancer studies have shown significant variability in overexpression of EGFR with rates ranging between $17 \%$ and $90 \%$ (Takehana et al, 2003; Hanawa et al, 2006; Pinto et al, 2007). Many of these studies have shown that overexpression of the EGFR is correlated with a worse prognosis (Ozawa et al, 1989; Wang et al, 2007). Therefore, it has been speculated that EGFR blockade may be an effective therapeutic strategy in this disease.

This phase II trial was designed to expand on two previous trials that investigated the role of EGFR tyrosine kinase inhibitors in upper GI adenocarcinomas (Dragovich et al, 2006; Ferry et al, 
2007). Both these single-agent trials demonstrated that there was modest activity in patients with tumours that were derived from the oesophagus and GEJ with no objective responses seen in patients with distal stomach cancer. The current trial was designed to determine the efficacy and toxicity of FOLFOX and erlotinib specifically in patients with oesophagus and GEJ adenocarcinoma with a particular emphasis on possible surrogate biomarkers.

\section{PATIENTS AND METHODS}

\section{Eligibility}

Patients with a histologic diagnosis of adenocarcinoma of the oesophagus or GEJ with measurable disease by Response Evaluation Criteria in Solid Tumours (RECIST) were considered eligible for the trial. In this study, oesophagus and GEJ tumours were defined by the Siewert classification (Siewert class I, II and III), which included cancers arising within $5 \mathrm{~cm}$ of the anatomic GE junction (distal oesophagus) or from the gastric cardia (Siewert and Stein, 1998). All patients enrolled on this study had an assessment of the GEJ made by imaging and by review of an endoscopic report. Patients with gastric cancers that did not involve the GEJ were excluded from participation.

Only patients with previously untreated metastatic disease were included. Previous radiotherapy or adjuvant chemotherapy was permitted as long as no treatment was received in the previous 12 months. Other eligibility requirements included ECOG performance status of 0 or 1 , peripheral neuropathy $\leqslant$ grade 1 , the ability to swallow oral medications, adequate haematologic (absolute neutrophil count $>1500 \mathrm{~mm}^{-3}$, platelets $>100000 \mathrm{~mm}^{-3}$ ), renal (creatinine clearance $>60 \mathrm{ml} \mathrm{min}^{-1}$ ) and hepatic function (total bilirubin $\leqslant 1.5 \times$ ULN, AST and ALT $\leqslant 3.0 \times$ ULN or $\leqslant 5.0 \times$ ULN if there is liver metastasis). Patients with a history of CNS metastasis, a history of active infections or other concomitant serious medical conditions were excluded from participation. Approval from institutional review boards from each participating centre was obtained. This study has been completed and registered at ClinicalTrials.gov, number NCT00591123.

\section{Study design}

This was a phase II open label, multi-centre trial administered under the not for profit TORI network. Erlotinib was provided by OSI Pharmaceuticals (Melville, NY, USA). The primary objective of the study was to assess overall response rate (ORR). Secondary objectives included assessment of toxicity, OS and progression-free survival (PFS), and exploratory analysis of translational endpoints in patient samples. Patients received modified FOLFOX6 (oxaliplatin $85 \mathrm{mg} \mathrm{m}^{-2}, 5-\mathrm{FU} 400 \mathrm{mg} \mathrm{m}^{-2}$, leucovorin $400 \mathrm{mg} \mathrm{m}^{-2}$, on day 1 followed by 5 -FU $2400 \mathrm{mg} \mathrm{m}^{-2}$ over $48 \mathrm{~h}$ ) and erlotinib $150 \mathrm{mg} \mathrm{day}^{-1}$ continuously. Two weeks constituted one cycle.

Treatment assessments Baseline assessments included history, physical examination including neurological and skin exam, CBC and platelet count, serum chemistries and diagnostic tumour imaging. During the study, history, physical exam, performance status, $\mathrm{CBC}$, chemistry and toxicity assessments were evaluated before the start of each cycle. Toxicity assessments were based on the National Cancer Institute Common Toxicity Criteria for Adverse Events, version 3.0 (http://ctep.cancer.gov/protocol Development/electronic_applications/ctc.htm). Tumour response measurements were done after every four cycles (8 weeks) and measurable lesions measured by CT scans were defined by modified RECIST criteria. Safety assessments consisted of regular monitoring of haematology, serum chemistries and physical exams with continuous recording of all adverse events (AE's).

Statistical design The primary objective of this trial was to assess objective response rate (RR), defined as the proportion of patients with complete response (CR) or partial response (PR). The objective RR and its $95 \%$ CI were estimated. Based on an ORR of $34.8 \%$, which was reported in the largest randomised trial that used the doublet of 5-FU and oxaliplatin, a target RR for the combination of FOLFOX and erlotinib was defined as $>44 \%$ to viewed as promising (Al-Batran et al, 2008). A planned sample size of 38 eligible patients would then provide a $90 \%$ CI with a type 1 error of $10 \%$. Progression-free survival was defined as the time from the date of initial treatment to first objective documentation of disease progression, or off-study, whichever came first, and OS was defined as the time from date of initial treatment to date of death or the last contact time if patient was still alive. Survival function was estimated using the Kaplan-Meier method and survival curves were generated for both PFS and OS. Data for all eligible and treated patients were done on all patients who received any treatment on this study.

Translational correlatives Representative paraffin blocks were required for all participating patients. Tissue blocks were obtained on 36 patients. The objectives of the correlative studies were (1) to assess the status of mutations in EGFR, KRAS, BRAF and PI3 kinase, (2) to assess the rates of EGFR and HER2 amplification and HER3 expression and (3) to investigate whether any of these markers were predictors of clinical benefit (as determined by RR, PFS and OS). The association between biomarker and objective response was investigated using the Fisher's exact test.

The EGFR, KRAS, BRAF and PI3 kinase mutation testing was done by purifying DNA using the MagneSil Genomic Fixed tissue System DNA Isolation Kit (Promega, Madison, WI, USA). Tumour areas of interest were selectively microdissected from the section. DNA was isolated from the collected cells using an extraction protocol designed for small paraffin-embedded tissues. The DNA was added to individual allele-specific PCR reactions targeting seven mutations in codons 12 and 13 of KRAS, seven mutations in exons 9 and 20 of the PI3 kinase gene, the T $>$ A transversion in exon 15 of the BRAF gene and the most prominent mutations, deletions and insertions in exons 18-21 of the EGFR gene. The KRAS mutation-specific reactions evaluate G12A, G12C, G12D, G12R, G12S, G12V and G13D whereas the PI3K panel covers E542K, E545K, E545G, E545D, E545A, H1047L and H1047R. The BRAF PCR targets the mutation associated with the V600E alteration and the EGFR panel includes reactions, which evaluate T790M, L858R, L861Q, G719A, G719S, G719C, S768I, 19 deletions in exon 19 and 3 insertions in exon 20. Each reaction is capable of detecting a mutation to $1-2 \%$ in a background of non-mutated DNA. All testing was performed using a real-time PCR platform (Clarient Inc., Alisa Viejo, CA, USA).

The EGFR and HER2 gene copy number were analysed using fluorescence in situ hybridisation (FISH) on $5 \mu \mathrm{m}$ thick paraffin sections. HER-2 gene amplification was assessed using the commercially available PathVysion HER-2 DNA probe kit (Vysis Corp., Downers Grove, IL, USA), which utilises a locus-specific probe mapping to the HER-2 gene 17q11.2-q12 (orange) and one control probe (green) mapping to the centromere of chromosome 17. The probe for identifying EGFR gene amplification is a commercially available probe cocktail that maps to the EGFR gene $7 \mathrm{p} 12$ (orange), with a control probe that maps to the centromere of chromosome 7 (green) (Vysis Corp.). An H\&E slide was evaluated for the tumour area by a pathologist and infiltrating tumour was circled. An unstained section was then pretreated and probed using standard treatment procedures. Gene amplification was assessed by analysing a minimum of 20 non-overlapping nuclei, containing at least one orange and one green signal. The ratio of orange to green signals was calculated. A ratio of $\geqslant 2.0$ is considered as amplified.

For the HER3 analysis, tumour areas of interest were identified and microdissected from the paraffin-embedded tissue section. 
The collected cells were digested and total RNA was purified from the sample using Qiagen RNeasy FFPE kit (Qiagen, Germantown, MD, USA). Total RNA was converted to cDNA using SuperScript III from Invitrogen (Carlsbad, CA, USA). Sample and control cDNA were subjected to real-time RT-PCR using an Applied Biosystems 7900HT (Applied Biosystems, Foster City, CA, USA). The expression values were calculated as a ratio of the target to reference gene transcript.

\section{RESULTS}

\section{Patient characteristics}

A total of 38 patients were enrolled between 21 December 2007 and 6 November 2009 from 12 participating sites. Table 1 lists the demographic and clinical characteristics of the patients. Per protocol, 5 of the 38 patients were not evaluable for best response; 2 withdrew consent after receiving one cycle and 3 additional patients had treatment toxicity and were changed to other therapies. Most patients were men $(87 \%)$ and the median age was 59. All patients had an ECOG PS of 0 or 1 (PS $0=60 \%$, PS1 $=40 \%$ ). In all, $95 \%$ of patients had metastatic disease and $5 \%$ were considered unresectable by a qualified thoracic surgeon. In total, $32 \%$ of patients had distal oesophageal cancers (Siewert class I) and $68 \%$ had tumours from the GEJ and cardia (Siewert class II and III). Altogether, $13 \%$ of patients had a history of an oesophagectomy, $16 \%$ had received previous radiation and $21 \%$ had received previous chemotherapy (either neoadjuvant or adjuvant). Of the eight patients that previously received chemotherapy, two received adjuvant chemoradiation (5-FU based), four received neoadjuvant chemoradiation (5-FU based) and two received neoadjuvant chemo alone (ECF).

\section{Treatment efficacy}

Of the 33 patients who were evaluable for response per protocol, there were 2 CRs and 15 PRs for an ORR of 51.5\% (95\% CI, 34.5$68.6 \%)$. In all, 15 responses have been formally confirmed resulting in a confirmed ORR of $45 \%$. When the five patients who did not undergo repeat evaluation are considered as progressive disease, the ORR is $45 \%$ (95\% CI, 30.0-61\%). An additional 11 patients (29\%) achieved stabilisation of their disease. The median follow-up for patients on study was 14.1 months.

Figure 1 demonstrates the Kaplan-Meier estimates of PFS and OS. Median PFS was 5.5 months (95\% CI, 3.1-7.5 months) and median OS was 11.0 months (95\% CI, 8.0-17.4 months).

Table I Patient demographics and clinical characteristics

Demographic or characteristic

Patients $(\mathbf{N}=\mathbf{3 8})$

Median age, years (range)

Female: male, number

ECOG PS: 0:1

Oesophagus: GEJ

Unresectable: metastatic

$59(36-79)$

5:33

23:15

12:26

2:36

Site of metastasis

Abdominal nodes: liver: lung: bone: other

$28: 19: 12: 5: 4$

Previous treatment:

Surgery: yes: no

Neoadjuvant or adjuvant chemo: yes: no

$5: 33$

$8: 30$

Previous chemo regimens:

Fluoropyrimidines/platinum (with adjuvant radiation)

Cisplatin/5-FU based (with neoadjuvant radiation)

Epirubicin/cisplatin/5-FU

Previous radiation therapy: yes: no

Neoadjuvant:adjuvant

2
4
2
$6: 32$
$4: 2$

Abbreviations: ECOG PS = Eastern Cooperative Group performance status; 5-Fu= 5-fluorouracil; GEJ = gastro-oesophageal junction.

\section{Safety data}

Adverse events associated with FOLFOX/erlotinib therapy are listed in Table 2. In all, $84 \%$ of the AEs were grade $1-2$ with $16 \%$ being grade $3-4$. The most common grade $3-4$ toxicities seen were non-haematologic: diarrhoea (24\%), anorexia (13\%), nausea/ vomiting $(11 \%)$, skin rash $(8 \%)$, fatigue $(11 \%)$ and peripheral neuropathy (8\%). Haematologic grade 3-4 toxicities consisted of $13 \%$ of patients experienced grade 3 neutropenia with one patient (3\%) having febrile neutropenia.

Erlotinib dose was modified in $39 \%$ of patients and were usually dose reductions to $100 \mathrm{mg}$.

\section{Biomarker analysis}

Tumour biopsies were available in 36 out of 38 (95\%) patients enrolled. Samples were analysed for mutations in EGFR, KRAS, BRAF and PI3 kinase. In addition, amplification by FISH was performed for EGFR and HER2 and expression by RT-PCR for HER3 levels. Table 3 lists the frequency of the molecular alterations. The frequency of mutations in KRAS was $8 \%$, and
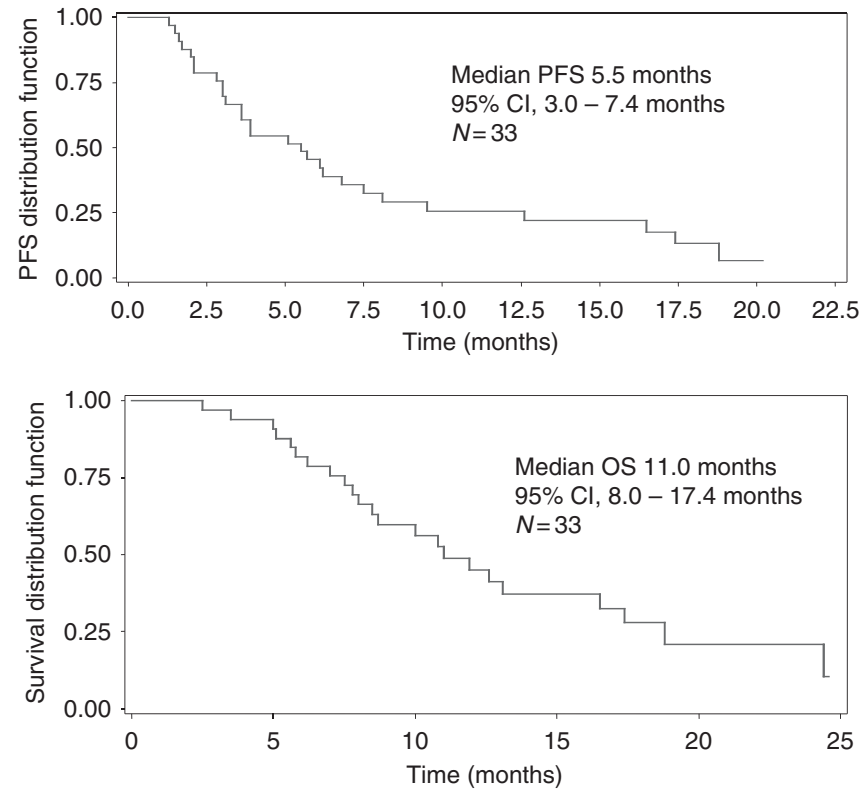

Figure I Progression-free survival (PFS) and overall survival (OS) (Kaplan-Meier estimates).

Table 2 Common grade 3 and 4 toxicities of the combination of FOLFOX and erlotinib $(N=38)$

\begin{tabular}{lcc}
\hline AE & Grade 3 (\%) & Grade 4 (\%) \\
\hline $\begin{array}{l}\text { Non-haematologica } \\
\text { Diarrhoea/dehydration }\end{array}$ & $9(24)$ & \\
Anorexia & $5(13)$ & \\
Nausea/vomiting & $3(8)$ & $\mid$ \\
Rash & $3(8)$ & \\
Fatigue & $3(8)$ & \\
Peripheral neuropathy & $3(8)$ & \\
Haematologica & & \\
Neutropenia & & \\
Neutropenic fever & $5(13)$ & \\
Lab only & & \\
Hypokalaemia & & \\
AST/ALT elevation & $2(5)$ & \\
\hline
\end{tabular}

Abbreviations: $\mathrm{AE}=$ adverse event; $\mathrm{ALT}=$ alanine aminotransferase; $\mathrm{AST}=$ aspartate aminotransferase. 
Table 3 Overall rates of KRAS, EGFR, BRAF, PI3Kinase mutations, EGFR and HER2 amplification by FISH and HER3 overexpression

\begin{tabular}{lcc}
\hline Biomarker & Yes N (\%) & No N (\%) \\
\hline KRAS mutation & $3(8)$ & $33(92)$ \\
EGFR mutation & $0(0)$ & $36(100)$ \\
BRAF mutation & $0(0)$ & $36(100)$ \\
PI3Kinase mutation & $1(3)$ & $35(97)$ \\
EGFR amplified (FISH) & $3(8)$ & $33(92)$ \\
HER2 amplified (FISH) & $7(19)$ & $29(81)$ \\
HER3 overexpressed (RT-PCR) & $4(11)$ & $32(89)$ \\
\hline
\end{tabular}

Abbreviations: $B R A F=v$-raf murine sarcoma viral oncogene; $E G F R=$ epidermal growth factor receptor; FISH = fluorescence in situ hybridisation; HER2 = human epidermal growth factor receptor 2; KRAS = Kirsten rat sarcoma viral oncogene; $\mathrm{PI}$ Kinase $=$ phosphatidylinositol 3 kinase; $\mathrm{RT}-\mathrm{PCR}=$ reverse transcriptase-PCR.

only one patient had a mutation in PI3 kinase. The EGFR and BRAF mutations were not detected. The rates of EGFR and HER2 amplification were $8 \%$ and $19 \%$, respectively. Given the small sample size, there was no predictive value to either RR, PFS or OS with any of the biomarkers analysed.

\section{DISCUSSION}

Historically, clinical trials in upper GI tract malignancies have been lumped together both histologically (squamous cell and adenocarcinomas) or location (oesophagus, GEJ and distal stomach). Over the last several years, it has become clear that these represent different biological entities both in terms of epidemiology, molecular biology and trends of incidence. In Western Europe and North America, the rates of GEJ cancers have increased, whereas those gastric tumours, which are $\mathrm{H}$ Pylori associated have fallen. Few trials have been reported specifically in patients with GEJ cancers (Stahl et al, 2009). To our knowledge, the trial reported herein is the first to examine the addition of a targeted agent to chemotherapy in this specific subset of upper GI cancers.

This phase II trial examined the efficacy and safety of the combination of FOLFOX chemotherapy and erlotinib in patients with advanced adenocarcinoma of the oesophagus and GEJ. The primary endpoint in this trial, objective RR was $51 \%$, which was similar to those recently reported in combination clinical trials with chemotherapies and anti-EGFR monoclonal antibodies in similar patient populations (Han et al, 2009; Pinto et al, 2009; Lordick et al, 2010). However, these trials contained different chemotherapy backbones and as recently reported in oesophageal adenocarcinoma, the monoclonal antibody cetuximab may be less biologically active in this group that anti-EGFR tyrosine kinase inhibitors (Gold et al, 2010). Interestingly, in a recently reported randomised phase II clinical trial evaluating various chemotherapy regimens with cetuximab, the highest PFS and OS were associated with the FOLFOX combination (Enzinger et al, 2010). Furthermore, our secondary endpoints of PFS and OS of 5.5 and 11.0 months, respectively, are also consistent with recent reports.

The combination of FOLFOX and erlotinib was generally well tolerated with few grade 3-4 toxicities consistent with a previous phase I study that examined this combination (Hanauske et al, 2007). Not surprisingly, an acneiform rash was the most common toxicity attributed to the addition of erlotinib in this trial. The protocol recommended aggressive treatment of the rash, which may explain the low rate $(8 \%)$ of grade 3 toxicities. The most common grade 3 or 4 toxicities seen were diarrhoea and dehydration (24\%) but these toxicities rarely required hospitalisation and was significantly reduced when erlotinib was decreased to $100 \mathrm{mg}$. However, based on these findings, a starting dose of erlotinib at $100 \mathrm{mg}$ could be considered in further studies. In addition, $8 \%$ of patients experienced grade 3 oxaliplatin-related peripheral neuropathy. While $39 \%$ of patients had a dose reduction to $100 \mathrm{mg}$ of erlotinib, there were no patients who stopped erlotinib for greater than a 2 -week period because of toxicity.

This study sought to examine some biological surrogates of EGFR pathway activation including EGFR and KRAS mutation status, EGFR and HER2 amplification and HER3 overexpression. Previous reports in lung cancer patients have demonstrated that clinical benefit from tyrosine kinase inhibitors is greater in patients whose tumours harbour an EGFR mutation (Lynch et al, 2004; Tsao et al, 2005; Maemondo et al, 2010). In our analysis, we did not detect any mutations in exons 18, 19 and 21. Although mutations in EGFR have been reported in oesophageal cancers, in one of the largest analyses to date, Dragovich et al (2006) did not detect any EGFR mutations in GEJ cancers (Guo et al, 2006; Kwak et al, 2006; Altiok et al, 2010). While we did detect evidence of EGFR gene amplification in $8 \%$ of patients (3 out of 36), consistent with previous reports, the small numbers precluded any correlation with clinical response (Janmaat et al, 2006).

On the basis of the recently reported results of the role of the HER2 oncogene in gastric and oesophageal cancers, we sought to investigate the frequency and correlation of HER 2 amplification. Our results indicate that $19 \%$ (7 out of 36 ) had evidence of HER2 amplification by FISH. The frequency of this alteration is consistent with the large randomised clinical trial of trastuzumab to chemotherapy (ToGA) trial (Bang et al, 2010). Not surprisingly and consistent with previous reports in other cancers, there was no correlation in patients treated with an EGFR inhibitor in our trial.

Recent reports have also implicated HER3 as having a critical role as a co-receptor for HER2 amplification as well as a marker for sensitivity to EGFR inhibition (Alimandi et al, 1995; Erjala et al, 2006; Engelman et al, 2007). Several studies have examined the rates of HER3 expression in gastric cancer by immunohistochemistry with one study showing correlation with a worse prognosis (Hayashi et al, 2008; Zhang et al, 2009). More recent studies have used RT-PCR to assess the rates of HER3 expression and using this technique, we found that 4 out of 36 tumours overexpressed HER3 (Witta et al, 2009). However, there was neither a correlation of HER3 with response nor an association with HER2 amplification by FISH. The role and most appropriate assays to measure HER3 clearly require further investigation.

Mutations in KRAS have recently become established as a negative predictive marker for the benefit of EGFR monoclonal antibodies in advanced colorectal cancer (Amado et al, 2008; Van Cutsem et al, 2009). Tajima et al (2007) compared the incidence of KRAS mutations in gastric cardia adenocarcinomas and distal stomach cancers and reported a 7\% positive mutation rate in both groups. Although few trials have looked specifically at GEJ tumours, the $8 \%$ rate of KRAS mutation in this trial is consistent with reports in oesophageal and gastric cancers (Arber et al, 2000; Lord et al, 2000). In this trial, all three patients with a mutation in KRAS did achieve an objective PR but the small sample size precluded any statistical correlation.

This study had several limitations with the major weakness being that it was a single-arm, non-comparative study. Unfortunately, the small numbers of patients and the diversity of these diseases have made any biomarker correlations a great challenge. However, our study was unique in those specifically excluded patients with distal gastric cancer, a subset of this disease that has distinct epidemiology, molecular alterations and prognosis. Our study also adds to those that have explored translational correlatives in this rare group of cancers (Janmaat et al, 2006; Rojo et al, 2006; Han et al, 2009). With the emergence of GEJ cancer as an increasingly recognised distinct entity, it is anticipated that more clinical trials will focus on the subsets of this malignancies. This study treated only adenocarcinoma of the oesophagus and GEJ, a subgroup that based on previous studies may be more sensitive to EGFR inhibition. Ongoing studies that are currently randomising patients to chemotherapy with or without EGFR inhibitors will clarify the true biologic activity of these agents. 


\section{ACKNOWLEDGEMENTS}

This work was partially supported by Sanofi-Aventis pharmaceuticals and OSI pharmaceuticals. We thank Dr Ira Steinberg and
Dr Susanne Classen of Sanofi-Aventis and Carolyn Byrnes of OSI. We gratefully acknowledge Paul Choppa and Raaj Trivedi of Clarient for help with valuable technical assistance. This work was supported in part by the Dimitri family foundation, Chatsworth, CA, USA.

\section{REFERENCES}

Al-Batran SE, Hartmann JT, Probst S, Schmalenberg H, Hollerbach S, Hofheinz R, Rethwisch V, Seipelt G, Homann N, Wilhelm G, Schuch G, Stoehlmacher J, Derigs HG, Hegewisch-Becker S, Grossmann J, Pauligk C, Atmaca A, Bokemeyer C, Knuth A, Jager E (2008) Phase III trial in metastatic gastroesophageal adenocarcinoma with fluorouracil, leucovorin plus either oxaliplatin or cisplatin: a study of the Arbeitsgemeinschaft Internistische Onkologie. J Clin Oncol 26(9): 1435-1442

Alimandi M, Romano A, Curia MC, Muraro R, Fedi P, Aaronson SA, Di Fiore PP, Kraus MH (1995) Cooperative signaling of ErbB3 and ErbB2 in neoplastic transformation and human mammary carcinomas. Oncogene 10(9): 1813-1821

Altiok S, Mezzadra H, Jagannath S, Tsottles N, Rudek MA, Abdallah N, Berman D, Forastiere A, Gibson MK (2010) A novel pharmacodynamic approach to assess and predict tumor response to the epidermal growth factor receptor inhibitor gefitinib in patients with esophageal cancer. Int J Oncol 36(1): 19-27

Amado RG, Wolf M, Peeters M, Van Cutsem E, Siena S, Freeman DJ, Juan T, Sikorski R, Suggs S, Radinsky R, Patterson SD, Chang DD (2008) Wild-type KRAS is required for panitumumab efficacy in patients with metastatic colorectal cancer. J Clin Oncol 26(10): 1626-1634

Arber N, Shapira I, Ratan J, Stern B, Hibshoosh H, Moshkowitz M, Gammon M, Fabian I, Halpern Z (2000) Activation of c-K-ras mutations in human gastrointestinal tumors. Gastroenterology 118(6): $1045-1050$

Bang YJ, Van Cutsem E, Feyereislova A, Chung HC, Shen L, Sawaki A, Lordick F, Ohtsu A, Omuro Y, Satoh T, Aprile G, Kulikov E, Hill J, Lehle M, Ruschoff J, Kang YK (2010) Trastuzumab in combination with chemotherapy versus chemotherapy alone for treatment of HER2positive advanced gastric or gastro-oesophageal junction cancer (ToGA): a phase 3, open-label, randomised controlled trial. Lancet 376(9742): $687-697$

Blot WJ, McLaughlin JK (1999) The changing epidemiology of esophageal cancer. Semin Oncol 26(5 Suppl 15): 2-8

Cunningham D, Starling N, Rao S, Iveson T, Nicolson M, Coxon F, Middleton G, Daniel F, Oates J, Norman AR (2008) Capecitabine and oxaliplatin for advanced esophagogastric cancer. $N$ Engl J Med 358(1): $36-46$

Dragovich T, McCoy S, Fenoglio-Preiser CM, Wang J, Benedetti JK, Baker AF, Hackett CB, Urba SG, Zaner KS, Blanke CD, Abbruzzese JL (2006) Phase II trial of erlotinib in gastroesophageal junction and gastric adenocarcinomas: SWOG 0127. J Clin Oncol 24(30): 4922-4927

Engelman JA, Zejnullahu K, Mitsudomi T, Song Y, Hyland C, Park JO, Lindeman N, Gale CM, Zhao X, Christensen J, Kosaka T, Holmes AJ, Rogers AM, Cappuzzo F, Mok T, Lee C, Johnson BE, Cantley LC, Janne PA (2007) MET amplification leads to gefitinib resistance in lung cancer by activating ERBB3 signaling. Science 316(5827): 1039-1043

Enzinger P, Burtness B, Hollis D, Niedzwiecki D, Ilson D, Benson AB, Mayer RJ, Goldberg RM (2010) CALGB 80403/ECOG 1206: a randomized phase II study of three standard chemotherapy regimens (ECF, IC, FOLFOX) plus cetuximab in metastatic esophageal and GE junction cancer. J Clin Oncol 28: 15s (suppl; abstr 4006)

Erjala K, Sundvall M, Junttila TT, Zhang N, Savisalo M, Mali P, Kulmala J, Pulkkinen J, Grenman R, Elenius K (2006) Signaling via ErbB2 and ErbB3 associates with resistance and epidermal growth factor receptor (EGFR) amplification with sensitivity to EGFR inhibitor gefitinib in head and neck squamous cell carcinoma cells. Clin Cancer Res 12(13): 4103-4111

Ferry DR, Anderson M, Beddard K, Tomlinson S, Atherfold P, Obszynska J, Harrison R, Jankowski J (2007) A phase II study of gefitinib monotherapy in advanced esophageal adenocarcinoma: evidence of gene expression, cellular, and clinical response. Clin Cancer Res 13(19): 5869-5875

Gold PJ, Goldman B, Igbal S, Leichman LP, Zhang W, Lenz HJ, Blanke CD (2010) Cetuximab as second-line therapy in patients with metastatic esophageal adenocarcinoma: a phase II Southwest Oncology Group Study (S0415). J Thorac Oncol 5(9): 1472-1476

Guo M, Liu S, Lu F (2006) Gefitinib-sensitizing mutations in esophageal carcinoma. N Engl J Med 354(20): 2193-2194
Han SW, Oh DY, Im SA, Park SR, Lee KW, Song HS, Lee NS, Lee KH, Choi IS, Lee MH, Kim MA, Kim WH, Bang YJ, Kim TY (2009) Phase II study and biomarker analysis of cetuximab combined with modified FOLFOX6 in advanced gastric cancer. Br J Cancer 100(2): 298-304

Hanauske AR, Cassidy J, Sastre J, Bolling C, Jones RJ, Rakhit A, Fettner S, Brennscheidt U, Feyereislova A, Diaz-Rubio E (2007) Phase 1b dose escalation study of erlotinib in combination with infusional 5-Fluorouracil, leucovorin, and oxaliplatin in patients with advanced solid tumors. Clin Cancer Res 13(2 Pt 1): 523-531

Hanawa M, Suzuki S, Dobashi Y, Yamane T, Kono K, Enomoto N, Ooi A (2006) EGFR protein overexpression and gene amplification in squamous cell carcinomas of the esophagus. Int J Cancer 118(5): 1173-1180

Hayashi M, Inokuchi M, Takagi Y, Yamada H, Kojima K, Kumagai J, Kawano T, Sugihara K (2008) High expression of HER3 is associated with a decreased survival in gastric cancer. Clin Cancer Res 14(23): 7843-7849 Janmaat ML, Gallegos-Ruiz MI, Rodriguez JA, Meijer GA, Vervenne WL, Richel DJ, Van Groeningen C, Giaccone G (2006) Predictive factors for outcome in a phase II study of gefitinib in second-line treatment of advanced esophageal cancer patients. J Clin Oncol 24(10): 1612-1619

Jemal A, Siegel R, Ward E, Hao Y, Xu J, Thun MJ (2009) Cancer statistics, 2009. CA Cancer J Clin 59(4): 225-249

Kwak EL, Jankowski J, Thayer SP, Lauwers GY, Brannigan BW, Harris PL, Okimoto RA, Haserlat SM, Driscoll DR, Ferry D, Muir B, Settleman J, Fuchs CS, Kulke MH, Ryan DP, Clark JW, Sgroi DC, Haber DA, Bell DW (2006) Epidermal growth factor receptor kinase domain mutations in esophageal and pancreatic adenocarcinomas. Clin Cancer Res 12(14 Part 1): $4283-4287$

Lord RV, O'Grady R, Sheehan C, Field AF, Ward RL (2000) K-ras codon 12 mutations in Barrett's oesophagus and adenocarcinomas of the oesophagus and oesophagogastric junction. J Gastroenterol Hepatol 15(7): $730-736$

Lordick F, Luber B, Lorenzen S, Hegewisch-Becker S, Folprecht G, Woll E, Decker T, Endlicher E, Rothling N, Schuster T, Keller G, Fend F, Peschel C (2010) Cetuximab plus oxaliplatin/leucovorin/5-fluorouracil in first-line metastatic gastric cancer: a phase II study of the Arbeitsgemeinschaft Internistische Onkologie (AIO). Br J Cancer 102(3): 500-505

Lynch TJ, Bell DW, Sordella R, Gurubhagavatula S, Okimoto RA, Brannigan BW, Harris PL, Haserlat SM, Supko JG, Haluska FG, Louis DN, Christiani DC, Settleman J, Haber DA (2004) Activating mutations in the epidermal growth factor receptor underlying responsiveness of non-small-cell lung cancer to gefitinib. N Engl J Med 350(21): 2129-2139

Maemondo M, Inoue A, Kobayashi K, Sugawara S, Oizumi S, Isobe H, Gemma A, Harada M, Yoshizawa H, Kinoshita I, Fujita Y, Okinaga S, Hirano $H$, Yoshimori K, Harada T, Ogura T, Ando M, Miyazawa $H$, Tanaka T, Saijo Y, Hagiwara K, Morita S, Nukiwa T (2010) Gefitinib or chemotherapy for non-small-cell lung cancer with mutated EGFR. $N$ Engl $J$ Med 362(25): $2380-2388$

Marsman WA, Tytgat GN, ten Kate FJ, van Lanschot JJ (2005) Differences and similarities of adenocarcinomas of the esophagus and esophagogastric junction. J Surg Oncol 92(3): 160-168

Ozawa S, Ueda M, Ando N, Shimizu N, Abe O (1989) Prognostic significance of epidermal growth factor receptor in esophageal squamous cell carcinomas. Cancer 63(11): 2169-2173

Pinto C, Di Fabio F, Barone C, Siena S, Falcone A, Cascinu S, Rojas Llimpe FL, Stella G, Schinzari G, Artale S, Mutri V, Giaquinta S, Giannetta L, Bardelli A, Martoni AA (2009) Phase II study of cetuximab in combination with cisplatin and docetaxel in patients with untreated advanced gastric or gastro-oesophageal junction adenocarcinoma (DOCETUX study). Br J Cancer 101(8): 1261-1268

Pinto C, Di Fabio F, Siena S, Cascinu S, Rojas Llimpe FL, Ceccarelli C, Mutri V, Giannetta L, Giaquinta S, Funaioli C, Berardi R, Longobardi C, Piana E, Martoni AA (2007) Phase II study of cetuximab in combination with FOLFIRI in patients with untreated advanced gastric or gastroesophageal junction adenocarcinoma (FOLCETUX study). Ann Oncol 18(3): $510-517$ 
Rojo F, Tabernero J, Albanell J, Van Cutsem E, Ohtsu A, Doi T, Koizumi W, Shirao K, Takiuchi H, Ramon y Cajal S, Baselga J (2006) Pharmacodynamic studies of gefitinib in tumor biopsy specimens from patients with advanced gastric carcinoma. J Clin Oncol 24(26): $4309-4316$

Siewert JR, Stein HJ (1998) Classification of adenocarcinoma of the oesophagogastric junction. Br J Surg 85(11): 1457-1459

Stahl M, Walz MK, Stuschke M, Lehmann N, Meyer HJ, Riera-Knorrenschild J, Langer P, Engenhart-Cabillic R, Bitzer M, Konigsrainer A, Budach W, Wilke H (2009) Phase III comparison of preoperative chemotherapy compared with chemoradiotherapy in patients with locally advanced adenocarcinoma of the esophagogastric junction. J Clin Oncol 27(6): 851-856

Tajima Y, Yamazaki K, Makino R, Nishino N, Masuda Y, Aoki S, Kato M, Morohara K, Kusano M (2007) Differences in the histological findings, phenotypic marker expressions and genetic alterations between adenocarcinoma of the gastric cardia and distal stomach. Br J Cancer 96(4): $631-638$

Takehana T, Kunitomo K, Suzuki S, Kono K, Fujii H, Matsumoto Y, Ooi A (2003) Expression of epidermal growth factor receptor in gastric carcinomas. Clin Gastroenterol Hepatol 1(6): $438-445$
Tsao MS, Sakurada A, Cutz JC, Zhu CQ, Kamel-Reid S, Squire J, Lorimer I, Zhang T, Liu N, Daneshmand M, Marrano P, da Cunha Santos G, Lagarde A, Richardson F, Seymour L, Whitehead M, Ding K, Pater J, Shepherd FA (2005) Erlotinib in lung cancer - molecular and clinical predictors of outcome. $N$ Engl J Med 353(2): 133-144

Van Cutsem E, Kohne CH, Hitre E, Zaluski J, Chang Chien CR, Makhson A, $\mathrm{D}^{\prime}$ Haens G, Pinter T, Lim R, Bodoky G, Roh JK, Folprecht G, Ruff P, Stroh C, Tejpar S, Schlichting M, Nippgen J, Rougier P (2009) Cetuximab and chemotherapy as initial treatment for metastatic colorectal cancer. $N$ Engl J Med 360(14): 1408-1417

Wang KL, Wu TT, Choi IS, Wang H, Resetkova E, Correa AM, Hofstetter WL, Swisher SG, Ajani JA, Rashid A, Albarracin CT (2007) Expression of epidermal growth factor receptor in esophageal and esophagogastric junction adenocarcinomas: association with poor outcome. Cancer 109(4): 658-667

Witta SE, Dziadziuszko R, Yoshida K, Hedman K, Varella-Garcia M, Bunn Jr PA, Hirsch FR (2009) ErbB-3 expression is associated with E-cadherin and their coexpression restores response to gefitinib in non-small-cell lung cancer (NSCLC). Ann Oncol 20(4): 689-695

Zhang XL, Yang YS, Xu DP, Qu JH, Guo MZ, Gong Y, Huang J (2009) Comparative study on overexpression of HER2/neu and HER3 in gastric cancer. World J Surg 33(10): 2112-2118

This work is published under the standard license to publish agreement. After 12 months the work will become freely available and the license terms will switch to a Creative Commons Attribution-NonCommercial-Share Alike 3.0 Unported License. 